\title{
Strategi Pengembangan Kerajinan Rotan di Desa Sungai Limas Kecamatan Haur Gading Kabupaten Hulu Sungai Utara
}

\section{(The Development Strategy of Rattan in Sungai Limas Village Haur Gading District Hulu Sungai Utara Regency)}

\author{
Purna Kusumayana $^{1)}$ \& Ahmad Syarif ${ }^{2)}$ \\ Program Studi Agribisnis, Sekolah Tinggi Ilmu Pertanian Amuntai \\ ${ }^{1)}$ kusumayanapurna@yahoo.com \\ 2)ahmadsyarif@yahoo.com
}

\begin{abstract}
ABSTRAK
Penelitian ini bertujuan untuk mengetahui kekuatan, kelemahan, peluang serta ancaman dalam pengembangan kerajinan di Desa Sungai Limas Kabupaten Hulu Sungai Utara, dan alternatif strategi pengembangannya di Desa Sungai Limas Kabupaten Hulu Sungai Utara. Berdasarkan hasil penelitian dari analisis matrik IFE didapat total skor 2,767 dan matrik EFE didapat total skor 2,939 dimana pada matrik IE menempatkan pada kuadran V yaitu strategi jaga dan pertahankan (hold and maintain). Strategi yang dapat diterapkan pada posisi ini adalah strategi penetrasi pasar dan pengembangan produk.
\end{abstract}

Kata Kunci: Strategi, pengembangan, kerajinan, Matrik IE.

\section{ABSTRACT}

This study aims to determine the strengths, weaknesses, opportunities and threats in the development of handicrafts in the Sungai Limas village of Hulu Sungai Utara, and alternative development strategies in the Sungai Limas village of Hulu Sungai Utara. Based on the results obtained from the analysis of IFE matrix total score of 2.767 and EFE matrices obtained a total score of 2.939 where the matrix V IE placed on the strategic quadrant keep and maintain (hold and maintain). Strategies that can be applied to this position is a strategic market penetration and product development.

Keywords: Strategy, development, craft, IE matrix.

\section{PENDAHULUAN}

Rotan merupakan salah satu hasil hutan yang banyak diminati setelah kayu. Hal ini disebabkan karena rotan memiliki sifat yang unik, mudah untuk diolah, kuat dan memiliki penampilan yang cukup menarik. Keunggulan rotan yang tidak kalah dari kayu tersebut, menjadikan komoditi rotan banyak dimanfaatkan sebagai bahan baku dalam industri khususnya furniture (Januminro, 2000). Peminat rotan tidak hanya berasal dari dalam negeri tetapi juga dari luar negeri. Diperkirakan hampir $80 \%$ keperluan rotan dunia dipasok oleh Indonesia. Namun potensi rotan yang cukup banyak tersebut ternyata tidak sejalan dengan perkembangan industri pengolahannya (Dransfield, 1996).

Perkembangan produksi kerajinan rotan di Kabupaten Hulu Sungai Utara dari tahun ke tahun cukup meningkat. Di Kecamatan Haur Gading kerajinan rotan diusahakan di Desa Sungai Limas dengan 93 unit usaha. Usaha kerajinan rotan yang ada di Desa Sungai Limas termasuk industri rumah tangga karena merupakan penghasilan sampingan masyarakat di Desa Sungai Limas dengan tujuan dapat membantu dan menambah pendapatan keluarga masingmasing (Dinas Perindustrian dan Perdagangan, 2011).

Menghadapi persaingan di pasar industri kerajinan dapat memilih dan mengimplementasikan ke dalam bentuk strategi pengembangan yang dipandang tepat. Keberhasilan industri dalam memenangkan persaingan sangat tergantung pada strategi pengembangan yang dipilih dan diaplikasikan dalam pemasaran. Pengembangan strategi pemasaran ini dipengaruhi beberapa hal, antara lain dari faktor internal dan faktor eksternal perusahaan. 
Faktor internal perusahaan dapat dikelola dengan baik, sehingga dapat dimanfaatkan sebagai kekuatan untuk menerapkan salah satu strategi pemasaran yang dapat dilakukan, sedangkan faktor eksternal harus dipantau agar mampu mengeksploitasi peluang bisnis yang ada dan dapat mengatasi ancaman bisnis di lingkungan industri. Oleh karena itu fokus dan perhatian manajemen harus diarahkan pada perumusan strategi yang tepat dengan memanfaatkan faktor internal dan faktor eksternal, sehingga menjadi kekuatan dalam menghadapi persaingan di pasar (Umar, 2010).

Penelitian ini bertujuan mengidentifikasi kekuatan, kelemahan, peluang, dan ancaman serta menentukan strategi pengembangan usaha kerajinan rotan di Desa Sungai Limas Kecamatan Haur Gading.

\section{METODE PENELITIAN}

Penelitian ini dilakukan di Desa Sungai Limas Kecamatan Haur Gading Kabupaten Hulu Sungai Utara. Penelitian dilaksanakan dari bulan Oktober 2012 Januari 2013.

Data yang dikumpulkan terdiri dari data primer dan data sekunder. Data primer berasal dari wawancara langsung kepada responden dengan menggunakan daftar pertanyaan yang sudah disiapkan. Data sekunder diperoleh dari instansi-instansi yang terkait serta studi pustaka dari berbagai media yang berhubungan dengan penelitian ini.

Tabel 1. Identifikasi kekuatan dan kelemahan
Penelitian ini merupakan penelitian deskriptif kualitatif. Data dikumpulkan dengan metode purposive sampling sebanyak 93 pengrajin usaha rotan untuk pihak internal. Sedangkan pihak eksternal diperoleh dari Kepala Dinas Perindustrian dan Perdagangan, Kabid Industri Dinas Perindustrian dan Perdagangan Kabupaten Hulu Sungai Utara, dan Kepala Desa Sungai Limas.

Analisa data yang digunakan adalah analisis SWOT (Strength, Weakness, Opportunity, Threats) yaitu untuk mengetahui kekuatan, kelemahan, peluang, dan ancaman dalam menentukan strategi perusahaan (Rangkuti, 2004). Beberapa alat analisis yang digunakan antara lain: Analisis Matriks Internal and External Factor Evaluation (IFE-EFE), Analisis Matriks IE ( internal - Eksternal ), Analisis Matriks SWOT (Strengths, Weakness, Oppotunities, dan Threats) (David, 2007).

\section{HASIL DAN PEMBAHASAN}

\section{Analisis Lingkungan Internal}

Lingkungan internal merupakan lingkungan yang berada di dalam perusahaan yang memiliki implikasi langsung dan khusus pada perusahaan. Analisis lingkungan internal dilakukan untuk mengetahui kekuatan dan kelemahan yang dimiliki usaha kerajinan rotan di desa Sungai Limas Kecamatan Haur Gading Kabupaten Hulu Sungai Utara. Adapun hasil analisis faktor internal dapat dilihat pada tabel berikut :

\begin{tabular}{ll}
\hline \multicolumn{1}{c}{ Kekuatan } & \multicolumn{1}{c}{ Kelemahan } \\
\hline - Bisa memenuhi motif yang diinginkan konsumen & - Modal terbatas masih menggunakan modal sendiri \\
- Adanya loyalitas konsumen & - Tidak ada pencatatan laporan keuangan \\
- Distribusi cukup luas & - Masih kurangnya promosi \\
- Kualitas bahan baku baik & - Tidak ada visi dan misi \\
- Produk yang dihasilkan beragam & $\bullet$ Memakai tenaga kerja dalam keluarga \\
- Harga bisa bersaing dengan produk lain & \\
\hline
\end{tabular}

Kekuatan (strengths) disini merupakan unsur yang mengacu kepada keunggulan kompetitif dan kompetesi lainnya yang dianggap dapat mempengaruhi usaha. Sedangkan Kelemahan (weaknesess) merupakan hambatan yang membatasi pada pengembangan strategi usaha kerajinan rotan. 


\section{Analisis Lingkungan Eksternal}

Lingkungan eksternal mencakup ancaman dan peluang utama yang dihadapi sehingga perusahaan mampu

Tabel 2. Identifikasi peluang dan ancaman memformulasikan strategi untuk mengambil keuntungan dari peluang dan menghindari atau mengurangi dampak dari ancaman. Hasil analisis faktor eksternal adalah sebagai berikut :

\begin{tabular}{lll}
\hline \multicolumn{1}{c}{ Peluang } & \multicolumn{2}{c}{ Ancaman } \\
\hline - Pada bulan rajab-syawal kebanjiran pesanan & - Ketidakpuasan konsumen terhadap produk \\
- Keadaan perekonomian membaik sehingga adanya & - Sikap masyarakat yang kurang mencintai produk \\
peluang pemasaran & lokal \\
$\begin{array}{l}\text { - Hubungan baik dengan pemasok } \\
\text { - Pengadaan pelatihan dan pameran dari pemerintah }\end{array}$ & $\begin{array}{l}\text { Semakin meningkatnya pesaing dari produk } \\
\text { - Perkembanganti }\end{array}$ \\
& $\begin{array}{l}\text { Turunnya tingkat pendapatan masyarakat sehingga } \\
\text { daya beli menurun }\end{array}$ \\
& - Bahan baku terbatas sehingga harga naik \\
\hline
\end{tabular}

Peluang (opportunities) merupakan unsur yang menyediakan kondisi yang menguntungkan untuk membatasi penghalang dan Ancaman (threats) merupakan kondisi yang dapat menghalangi usaha mencapai tujuan.

\section{Matriks IFE}

Analisis matriks IFE dilakukan dengan mengindentifikasi faktor-faktor internal yang terdiri dari kekuatan dan kelemahan yang dimiliki usaha kerajinan rotan. Setelah itu dilanjutkan dengan memberi pembobotan dan rating, pemberian rating untuk menunjukkan apakah faktorfaktor tersebut merupakan kekuatan yang besar atau yang kecil bagi usaha kerajinan rotan, rating yang tertinggi yaitu 4 diberikan pada faktor yang menjadi kekuatan utama dan sampai terendah yaitu 1 yang menjadi kelemahan utama usaha kerajinan rotan.Hasil perolehan bobot dan rating dikalikan sehingga dapat diketahui skor pembobotan.

Tabel 3. Matriks IFE usaha kerajinan rotan

\begin{tabular}{|c|c|c|c|}
\hline Faktor Strategi Internal & Bobot & Rating & $\begin{array}{c}\text { Skor } \\
\text { Pembobotan }\end{array}$ \\
\hline \multicolumn{4}{|l|}{ Kekuatan } \\
\hline - Bisa memenuhi semua jenis motif yang diinginkan konsumen & 0,155 & 4 & 0,620 \\
\hline - Adanya loyalitas konsumen & 0,155 & 4 & 0,620 \\
\hline - Distribusi cukup luas & 0,145 & 4 & 0,580 \\
\hline - Kualitas bahan baku baik & 0,150 & 3 & 0,450 \\
\hline - Produk yang dihasilkan beragam & 0,059 & 3 & 0,019 \\
\hline - Harga bisa bersaing dengan produk lain & 0,059 & 3 & 0,019 \\
\hline \multicolumn{4}{|l|}{ Kelemahan } \\
\hline - Modal terbatas masih menggunakan modal sendiri & 0,091 & 1 & 0,091 \\
\hline - Tidak ada pencatatan laporan keuangan & 0,054 & 2 & 0,108 \\
\hline - Masih kurangnya kegiatan promosi & 0,054 & 2 & 0,108 \\
\hline - Tidak ada visi dan misi & 0,027 & 2 & 0,054 \\
\hline - Memakai tenaga kerja dalam keluarga & 0,049 & 2 & 0,098 \\
\hline Total & 1.000 & & 2,767 \\
\hline
\end{tabular}

\section{Matriks EFE}

Analisis matriks EFE dilakukan dengan mengindentifikasi faktor-faktor eksternal yang terdiri dari peluang dan ancaman yang dimiliki usaha kerajinan rotan. Pemberian rating untuk menunjukkan apakah faktor-faktor tersebut merupakan peluang yang besar atau yang kecil bagi usaha kerajinan rotan, rating yang tertinggi yaitu 4 diberikan pada faktor yang menjadi 
peluang utama dan sampai terendah yaitu 1 yang menjadi ancaman utama usaha kerajinan rotan. Hasil perolehan bobot dan rating dikalikan sehingga dapat diketahui skor pembobotan.

Tabel 4. Matriks EFE usaha kerajinan rotan

\begin{tabular}{|c|c|c|c|}
\hline Faktor Strategi Eksternal & Bobot & Rating & $\begin{array}{c}\text { Skor } \\
\text { Pembobotan }\end{array}$ \\
\hline \multicolumn{4}{|l|}{ Peluang } \\
\hline - Pada bulan rajab-syawal kebanjiran pesanan & 0,165 & 4 & 0,660 \\
\hline $\begin{array}{l}\text { - Keadaan perekonomian membaik sehingga adanya } \\
\text { peluang pemasaran }\end{array}$ & 0,121 & 4 & 0,484 \\
\hline - Hubungan baik dengan pemasok & 0,110 & 4 & 0,440 \\
\hline - Pengadaan pelatihan dan pameran dari pemerintah & 0,110 & 4 & 0,440 \\
\hline - Perkembangan teknologi yang semakin maju & 0,072 & 4 & 0,288 \\
\hline \multicolumn{4}{|l|}{ 'Ancaman } \\
\hline - Ketidakpuasan konsumen terhadap produk & 0,099 & 1 & 0,099 \\
\hline - Sikap masyarakat yang kurang mencintai produk lokal & 0,110 & 1 & 0,110 \\
\hline - Semakin meningkatnya pesaing dari produk pengganti & 0,099 & 2 & 0,198 \\
\hline $\begin{array}{l}\text { - Turunnya tingkat pendapatan masyarakat sehingga } \\
\text { daya beli menurun }\end{array}$ & 0,072 & 2 & 0,144 \\
\hline - Bahan baku terbatas sehingga harga naik & 0,038 & 2 & 0,076 \\
\hline Total & 1,000 & & 2,939 \\
\hline
\end{tabular}

\section{Analisis Matriks IE}

Dari hasil yang diperoleh pada matriks IFE dan EFE maka dapat disusun selanjutnya dengan analisis matriks InternalEksternal (IE) sehingga dapat diketahui posisi usaha kerajinan rotan dan matriks ini selanjutnya bisa digunakan untuk mempermudah dalam memberikan pemilihan alternatif strategi.

\begin{tabular}{|c|c|c|c|c|}
\hline \multirow{5}{*}{ 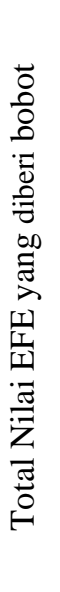 } & & \multicolumn{3}{|c|}{ Total Nilai IFE yang diberi bobot } \\
\hline & \multirow{2}{*}{4,0} & 4,0 & $2,767 \quad 2,0$ & 1,0 \\
\hline & & $\begin{array}{c}\text { I } \\
\text { Tumbuh dan } \\
\text { Bina }\end{array}$ & $\begin{array}{c}\text { II } \\
\text { bumbuh dan }\end{array}$ & $\begin{array}{c}\text { III } \\
\text { Pertahankan } \\
\text { dan Pelihara }\end{array}$ \\
\hline & 2,9 & $\begin{array}{c}\text { IV } \\
\text { Tumbuh dan } \\
\text { Bina }\end{array}$ & $\begin{array}{c}\text { V } \\
\text { Pertahankan } \\
\text { dan Pelihara }\end{array}$ & $\begin{array}{c}\text { VI } \\
\text { Panen dan } \\
\text { divestasi }\end{array}$ \\
\hline & 1,0 & $\begin{array}{c}\text { VII } \\
\text { Pertahankan } \\
\text { dan Pelihara }\end{array}$ & $\begin{array}{c}\text { VIII } \\
\text { Panen dan } \\
\text { Divestasi }\end{array}$ & $\begin{array}{c}\text { IX } \\
\text { Panen dan } \\
\text { Divestasi }\end{array}$ \\
\hline
\end{tabular}

Gambar 1. Posisi usaha kerajinan rotan pada Matriks IE

Berdasarkan posisi yang terlihat pada matriks IE berada pada posisi V. Posisi ini disebut pertahankan dan pelihara, strategi yang tepat digunakan dalam posisi ini adalah strategi penetrasi pasar dan pengembangan produk.
Strategi penetrasi pasar adalah suatu strategi untuk meningkatkan pangsa pasar pada produk atau jasa yang telah tersedia dengan cara usaha-usaha yang lebih agresif. Promosi harga, iklan, publisitas dan perluasan jaringan distribusi diperlukan dalam strategi penetrasi pasar untuk 
Purna Kusumayana \& Ahmad Syarif, Strategi pengembangan kerajinan rotan...

membantu usaha kerajinan rotan dalam meningkatkan penjualannya.

\section{KESIMPULAN}

Kekuatan utama usaha kerajinan rotan di Desa Sungai Limas adalah bisa memenuhi semua jenis motif yang diinginkan konsumen dan adanya loyalitas konsumen, sedangkan kelemahan utama adalah tidak ada visi dan misi dan modal terbatas karena menggunakan modal sendiri. Peluang utama yang dimiliki usaha kerajinan rotan adalah pada bulan rajab-syawal kebanjiran pesanan dan keadaan perekonomian membaik sehingga adanya peluang pemasaran, sedangkan ancaman utama usaha kerajinan rotan adalah ketidakpuasan konsumen terhadap produk dan bahan baku terbatas sehingga harga naik. Hasil Matris IE berdasarkan analisis lingkungan internal dengan menggunakan matrik IFE dengan total skor terbobot sebesar 2,767 sedangkan matrik EFE sebesar 2,939 menunjukkan posisi usaha kerajinan rotan berada di sel V yang menggambarkan Hold and Maintain (jaga dan pertahankan). Strategi yang tepat digunakan pada posisi ini adalah strategi penetrasi pasar dan pengembangan produk.

\section{DAFTAR PUSTAKA}

David. 2007. Manajemen Strategis: Konsepkonsep, Edisi kedua belas. Salemba Empat. Jakarta.

Dinas Perindustrian dan Perdagangan. 2011. Potensi Komoditi Unggulan Daerah Tahun 2011. Dinas Perindustrian dan Perdagangan. Kabupaten Hulu Sungai Utara.

Dransfield. 1996. Sumber Daya Nabati Asia Tenggara: Rotan. Yogyakarta: Gadjah Mada University Press bekerjasama dengan Prosea Indonesia.

Januminro. 2000. Rotan Indonesia.

Yogyakarta: Kanisius.
Rangkuti, F. 2004. Analisis SWOT, Teknik Membedah Kasus Bisnis. PT Gramedia Pustaka Utama. Jakarta.

Umar, H. 2010. Desain Penelitian Manajemen Strategik. PT Raja Grafindon Persada. Jakarta. 